\title{
Tripping of circuit breakers in PV installations due to zero sequence field impedance
}

\author{
B. Verhelst ${ }^{1,2}$, C. Debruyne ${ }^{1,2}$, J. Desmet ${ }^{1,2}$ \\ ${ }^{1}$ dept. Electrical Engineering - Lemcko \\ HoWest \\ Kortrijk, Belgium \\ bart.verhelst@howest.be
}

\begin{abstract}
On the roof of a wool processing company a $385 \mathrm{kWp}$ $P V$ installation is installed. When production of the installation is more than $60 \%$ of the rated power the circuit breaker trips. Measurements show high THD(U) of phase voltages and variable waveform of both voltage and current. Analysis of the installation showed that a $\mathbf{Y y}_{0}$ transformer is installed introducing a high zero sequence field impedance. Unbalance in the injected current combined with a zero sequence impedance leads to high voltage drops and distorted phase voltages. Measurements also show high RMS values of the current in the neutral conductor. Analyses show that the tripping of the circuit breaker is caused by the measurement method of the device itself. Higher current values are calculated due to multiple zero crossings of both voltage and current. This paper gives the practical measurement results, causes of errors and the solution to the stated problems.
\end{abstract}

Keywords - Solar power, transformer, tripping circuit breaker, measurement methode, zero sequence field impedance

\section{INTRODUCTION}

The 20/20/20 targets of the European Union lead to the massive use of renewable energy. Belgium has to produce $13 \%$ of his electrical energy out of renewable energy by 2020 [1]. In different regions Photo Voltaic (PV) installations are highly promoted caused by the high financial return by green current certificates [3]. Due to the large funding the exponential growth has led to situations of technically unconsidered investments, as shown in the following case.

On the roof of a wool processing company a $385 \mathrm{~kW}_{\mathrm{p}} \mathrm{PV}$ installation is integrated (Figure 1). The PV installation is divided on two roofs. On one roof, closest to the transformer, $230 \mathrm{~kW}_{\mathrm{p}}$ is installed with 41 one-phase invertors. Here the cable length to the General Low Voltage Distribution Board (GLVDB) is the shortest. On the second roof $155 \mathrm{~kW}_{\mathrm{p}}$ is installed with 21 invertors. In both cases the electrical distribution of the PV inverters is nearly balanced over the three phases.

The majority of the load in the company consist of three phase loads, mainly Variable Speed Drives (VSD) and Direct on line (DOL) induction motors (IM) to process the natural wool. Single phase loads, mostly lighting and IT equipment, are negligible with respect to the total load.

\author{
L. Vandevelde ${ }^{2}$ \\ ${ }^{2}$ Electrical Energy Laboratory \\ Dept. of Electrical Energy Systems and Automation \\ Ghent University, Belgium \\ lieven.vandevelde@ugent.be
}

At low irradiation, $(<1000 \mathrm{~W} /$ invertor $)$, no problems are reported. When irradiation increases more than $1000 \mathrm{~W} /$ invertor flicker is observed in the fluorescent lamps in the factory. After a period of \pm 5 minutes the main electronic trip circuit breaker activates. Only when the half of the panels is switched on, the flicker effect occurs but the circuit breaker does not react. The limited use of the PV installation, to prevent shutdown, leads to large production losses and increase of payback time [2].

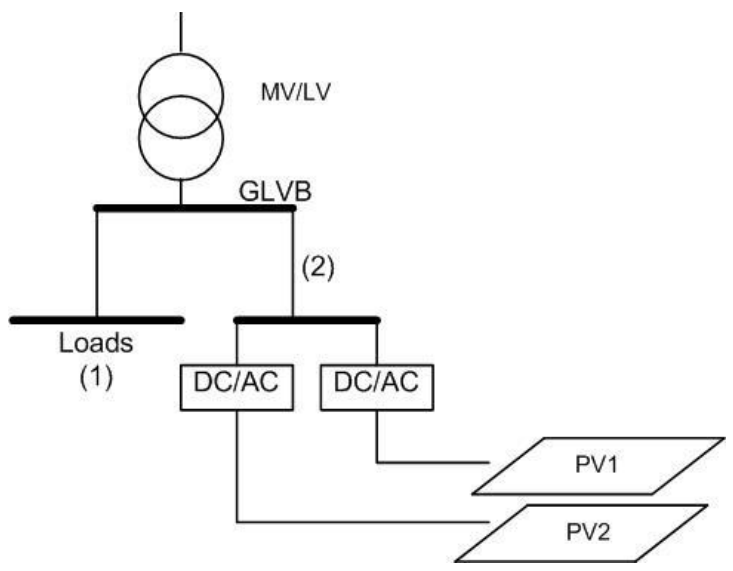

Figure 1: general situation

\section{THEORETICAL APPROACH}

\section{A. Symetrical components}

In a unbalanced three-phase system, line currents will flow unequal over the three phases. Asymmetric load conditions create a system of three asymmetric flows which are different in phase and magnitude. Currents can be divided into three components using the Fortescue transformation.

$$
\left|\begin{array}{c}
\bar{I}_{+} \\
\bar{I}_{-} \\
\bar{I}_{0}
\end{array}\right|=\frac{1}{3}\left|\begin{array}{ccc}
1 & a & a^{2} \\
1 & a^{2} & a \\
1 & 1 & 1
\end{array}\right| *\left|\begin{array}{c}
\bar{I}_{A} \\
\bar{I}_{B} \\
\bar{I}_{C}
\end{array}\right|
$$


The instantaneous sum of the currents equals zero in both positive and negative system. The zero sequence currents result in a neutral conductor current $\overline{I_{n}}=3 \overline{I_{0}}$. In absence of this conductor, a voltage unbalance will occur. In order to analyze unbalance both source and load can be represented by voltage sources (Figure 2).

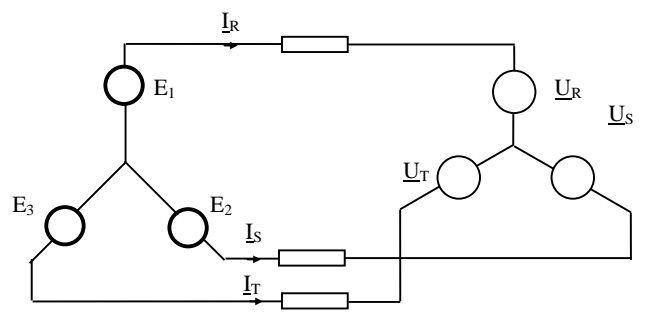

Figure 2: three phase system represented by three voltage sources

More specific the positive and negative current system create a balanced load for the transformer. These components also create in the primary winding a positive and negative system that is in balance with the system in the secondary winding. As a consequence the zero sequence component remains hence only the zero sequence impedance is of further importance.

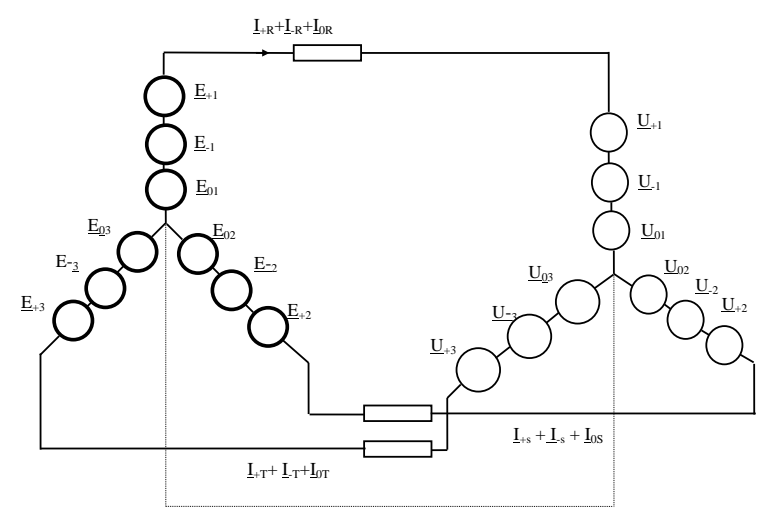

Figure 3: three phase system represented by their symmetrical components

\section{B. Theoretical approach of a $Y y_{0}$}

The transformer in this installation is a $\mathrm{Yy}_{0}$ configurator. Only on secondary side a neutral conductor is present.
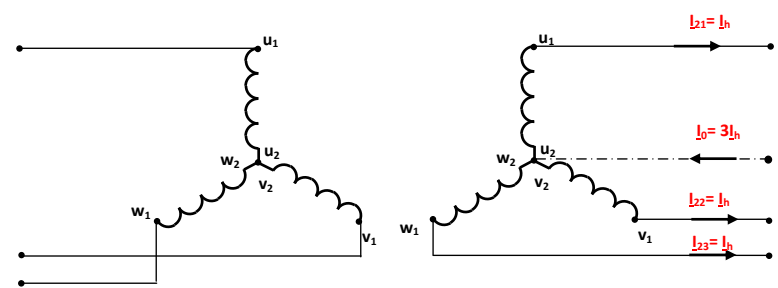

Figure 4: Yy transformer system

Since the primary winding is in a Wye configuration without neutral conductor, the zero sequence current in the secondary winding will not be transformed to the primary winding. As a consequence the secondary Amp Windings
(AW) are not balanced by the primary AW and a zero sequence flux system is created.

In case of a three core transformer these zero sequence fluxes close through the air and transformer tank. Since the zero sequence impedance $\bar{z}_{h}$ depends on the magnetic circuit one assumes that $\bar{z}_{h} \cong 0,7$ p.u.

In case of a 5 leg transformer or three one phase transformers, zero sequence fluxes will close through the free legs. Fluxes are damped and zero sequence currents create a zero sequence flux. In this case the zero sequence impedance has values up to 100 p.u. [8] Table 1 gives an overview of the zero sequence field reactance of different types of transformers.

Table 1: overview of the zero sequence field reactance as a factor of normal reactance

\begin{tabular}{|l|c|c|c|c|}
\hline & $\mathrm{Yy}_{\mathrm{n}}$ & $\mathrm{Dy}_{\mathrm{n}}$ & $\mathrm{Y}_{\mathrm{n}} \mathrm{Dy}$ & $\mathrm{Yz}_{\mathrm{n}}$ \\
\hline 3-leg & $3 \ldots 10$ & $0,65 \ldots 0,9$ & $1 \ldots 2,4$ & $0,10 \ldots 0,15$ \\
\hline 5-leg & $10 \ldots 100$ & 1 & $1 \ldots 2,4$ & $0,10 \ldots 0,15$ \\
\hline $\begin{array}{l}3 \mathrm{x} \text { one } \\
\text { phase }\end{array}$ & $10 \ldots 100$ & 1 & $1 \ldots 2,4$ & $0,10 \ldots 0,15$ \\
\hline
\end{tabular}

The zero sequence flux induces in both primary and secondary phase windings a zero sequence voltage. These add up with the three phase voltages. As a consequence unbalanced phase voltages will occur. Line voltages are not affected.

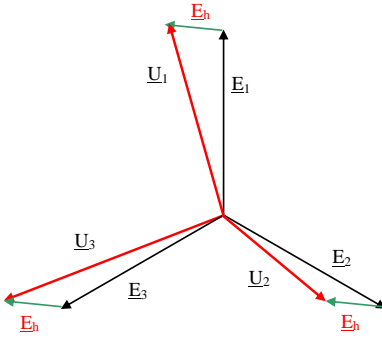

Figure 5: Vector diagram non symmetrical phase voltages

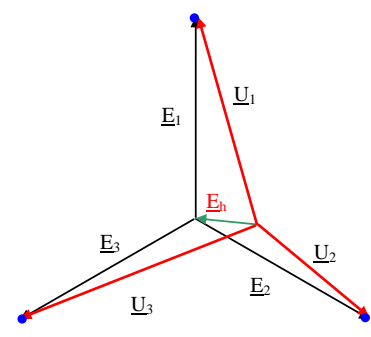

Figure 6: Vector diagram shift of the ground potential
In the primary windings the line voltages are imposed by the grid. The potential of the isolated neutral point is different from zero. Since unbalanced loads create unbalanced currents, the zero sequence current system will lead to a shift of the ground potential causing unequal phase voltages.

\section{MEASUREMENTS}

\section{A. General}

Measurements were done on the general low voltage board and the lighting circuits. Measurements were performed on a sunny day, with and without PV production. Three phase measurements were performed using a Fluke 435 Power quality analyzer.

\section{B. Measurement on the general low voltage board}

On the GLVDB measurements of THD(U), THD(I) and waveforms were performed during production with both PV 
installations active. Figure 7 and Figure 8 represent the $\mathrm{THD}(\mathrm{U})$ of the phase voltage and THD(I) of the line current.

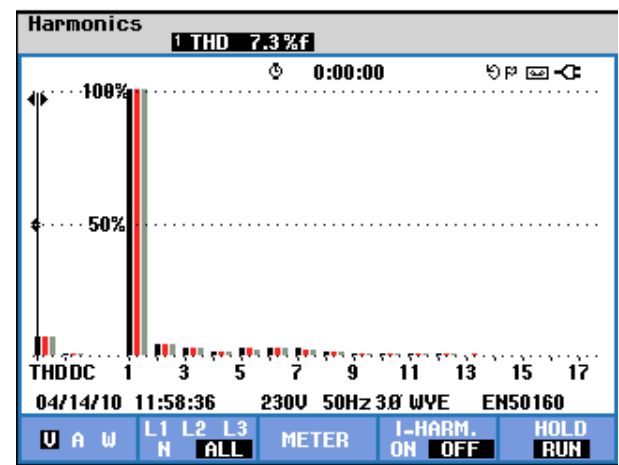

Figure 7: harmonic spectrum of the voltage on GLVDB with production

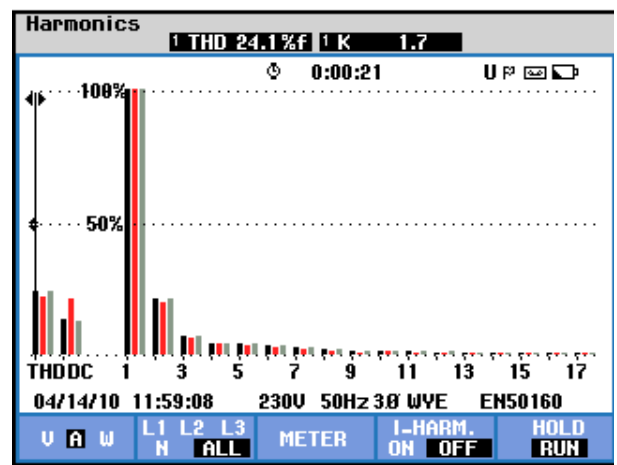

Figure 8: harmonic spectrum of the current on GLVDB with production

Figure 9 shows the wave shape of both voltage and current on one phase and Figure 10 shows the wave shape of the phase currents in the three phases and the neutral conductor. Table 2 gives the numerical values of both voltage and current.

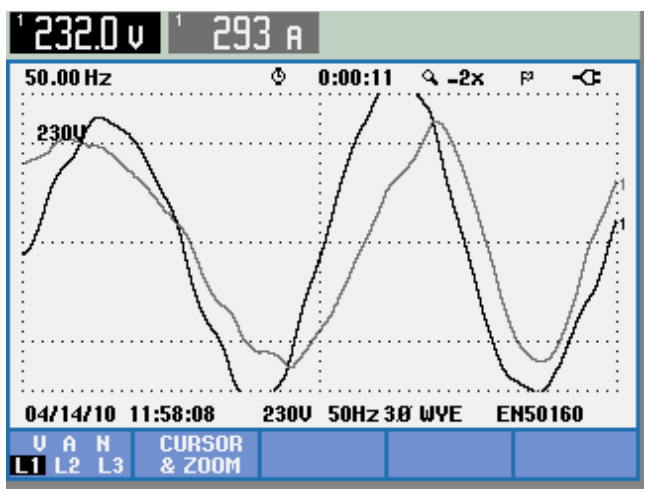

Figure 9: waveform phase voltage on phase 1 in case of production

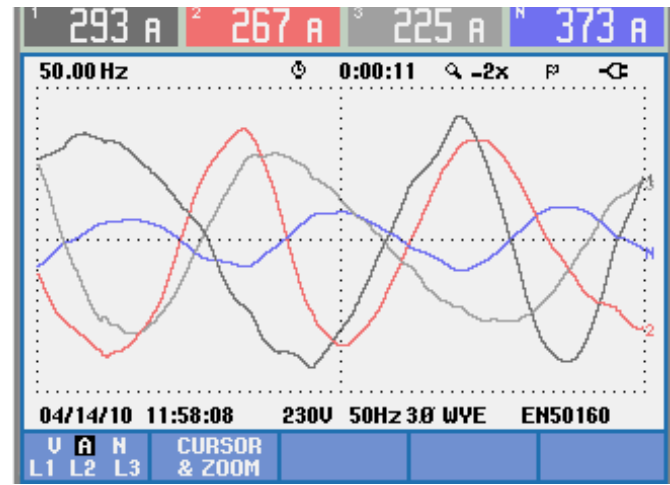

Figure 10: waveform phase current in case of production

Table 2: Measurement values

\begin{tabular}{|c|c|c|c|c|}
\hline Voltage & $\mathrm{L}_{1}$ & $\mathrm{~L}_{2}$ & $\mathrm{~L}_{3}$ & $\mathrm{~N}$ \\
\hline $\mathrm{V}_{\mathrm{RMS}}$ & 229.5 & 225.4 & 232.9 & 1.1 \\
\hline $\mathrm{V}_{\mathrm{pk}}$ & 381.3 & 377.2 & 376.4 & 2.8 \\
\hline $\mathrm{CF}$ & 1.66 & 1.67 & 1.62 & \\
\hline $\mathrm{Hz}$ & 49.99 & & & \\
\hline Current & $\mathrm{L}_{1}$ & $\mathrm{~L}_{2}$ & $\mathrm{~L}_{3}$ & $\mathrm{~N}$ \\
\hline $\mathrm{A}_{\mathrm{RMS}}$ & 297 & 298 & 253 & 407 \\
\hline$A_{p k}$ & 534 & 530 & 439 & 772 \\
\hline $\mathrm{CF}$ & 1.80 & 1.78 & 1.74 & 1.90 \\
\hline
\end{tabular}

\section{Measurement on the lighting circuits}

A first analysis was performed on the lighting circuits without the PV installation connected. The harmonic spectrum of the phase voltage is given in Figure 11, the THD(U) is 3\% and can be considered as normal value taking into account background pollution and present load conditions. Figure 12 gives the wave shape of the voltage.

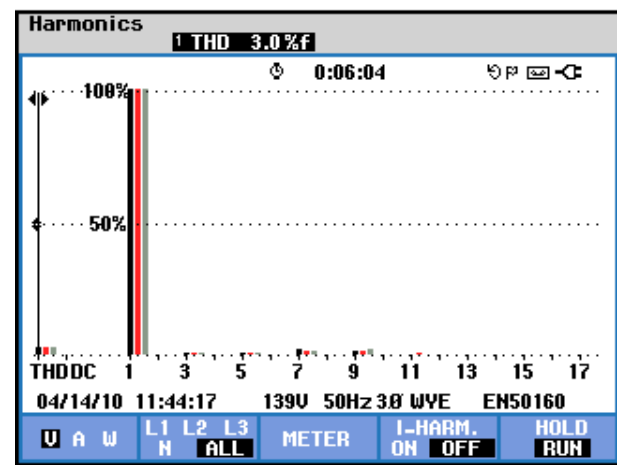

Figure 11: harmonic spectrum voltage without production 


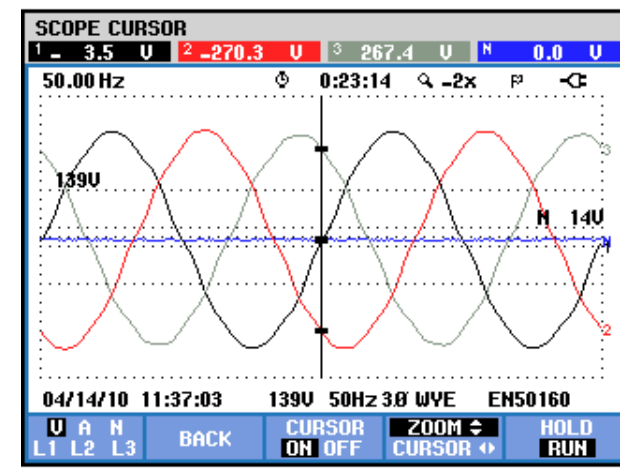

Figure 12: wave shape phase voltage without production

In a second analysis the PV installation was connected under similar load conditions. The harmonic spectrum is shown in Figure 13 where the $\operatorname{THD}(\mathrm{U})$ of the phase voltage is $9,5 \%$. Figure 14 gives the wave shape of the voltage.

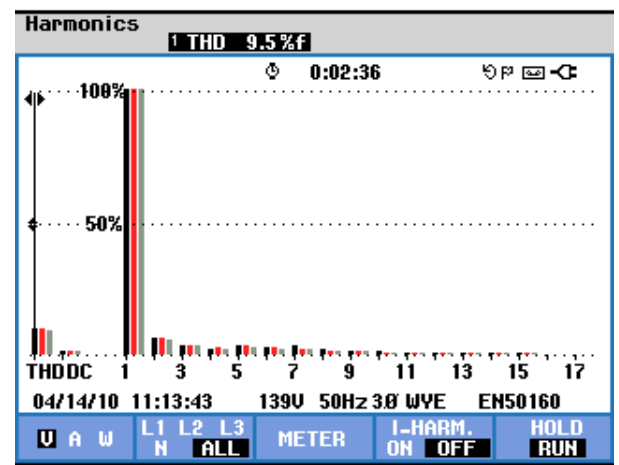

Figure 13: harmonic spectrum voltage with production

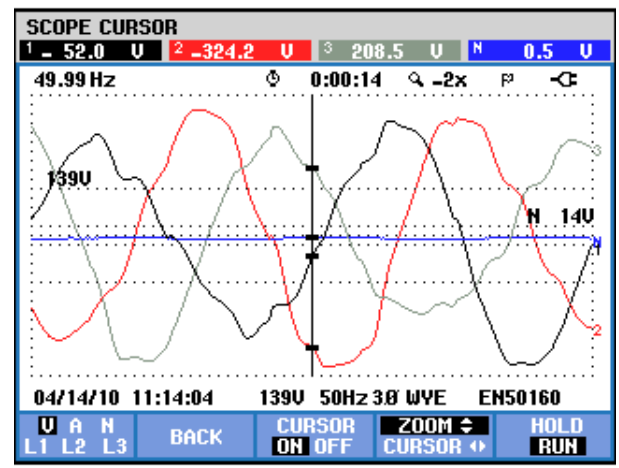

Figure 14: wave shape phase voltage with production

\section{EVALUATION OF THE MEASUREMENT RESULTS}

The measurements show for both measurement locations a high voltage distortion of phase voltage when production is sufficient. For inverter productions more than $60 \%$ of the installed capacity the THD(U) of the phase voltages increases from 7,3\% up to 9,5\%. With respect to the EN50160 standard, a $\mathrm{THD}(\mathrm{U})$ of more than $8 \%$ is not allowed [6]. Even more, the values of the total harmonic voltage fluctuate very quickly in time.

Based on the data shown in Figure 8 it could also be assumed that due to a $\operatorname{THD}(\mathrm{I})$ of $24,1 \%$, a relatively large current distortion is present. If the waveforms are considered they seem not to exceed a THD(I) of $24 \%$ (Figure 9 and Figure 10). The RMS value of the neutral conductor current reaches up to $407 \mathrm{~A}_{\mathrm{RMS}}$ (Table 2). Since the installation is built with a half section neutral conductor of $120 \mathrm{~mm}^{2}$ the maximum allowable RMS current in the neutral conductor is $344 \mathrm{~A}_{\mathrm{RMS}}$ [4] for single phase cables. As a consequence, it can be concluded that the neutral conductor is highly overloaded.

\section{CAUSE}

\section{A. Voltage distortion}

Measurements show large phase voltage shifts and distortions at the transformer terminals. This is not the regular configuration since Medium Voltage (MV) / Low Voltage (LV) transformers traditionally are exploited as $\mathrm{Dy}_{0}$ (Figure 15). This means that the imposed line voltages from the MV grid also impose the reference of the phase voltages at the low voltage side. Fortesque transformation indicates a low zero sequence field impedance (Table 1).

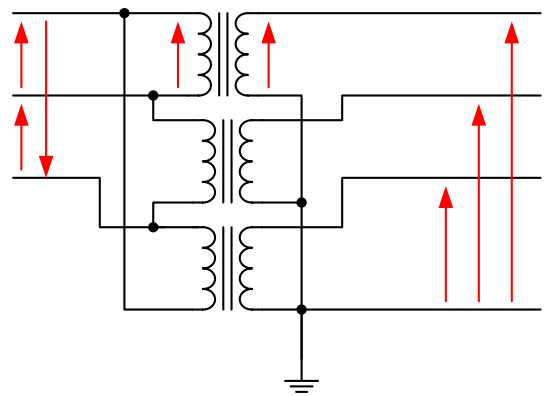

Figure 15: DY Transformer

As mentioned earlier the installation is equipped with a $\mathrm{Yy}_{0}$ transformer (Figure 16). This type of transformer does not impose the electric potential of the reference for the phase voltages, consequently the Fortesque transformation shows a high zero sequence field impedance (Table 1).

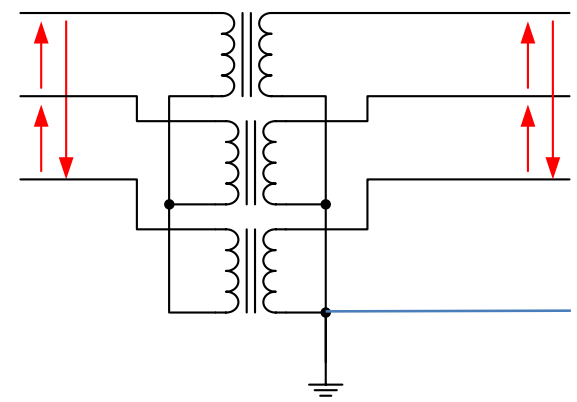

Figure 16: Yy Transformer

The PV installation is built using single phase inverters equally distributed over the three phases [5]. Consequently unbalanced injection and high zero sequence impedance will lead to high values of zero sequence voltages. This explains the distortion of the phase voltage.

Since an inverter is a voltage controlled current source a high voltage drop occurs over the zero sequence field impedance in case of high injected currents. The phase voltages are unbalanced and distorted while the line voltages 
remain constant. If unbalance is higher, more current is injected. This distortion also explains the flicker.

\section{B. Oscillating behavior of phase voltage and current}

Previous studies have shown that, for cable cross sections less than $150 \mathrm{~mm}^{2}$ [3], the voltage rises on the phase where most power is injected. Consequently, for the same power and an increased voltage the current should drop eventually leading to a equilibration.

However, the installation also includes VSD. These drives refer to line voltage. Consequently the line with the highest voltage holds the highest current. The interaction between load and source creates a oscillating behavior, mainly in function of the current controller speed of the inverter. This also explains why no stable measurements could be performed.

\section{RMS Current and FFT measurement Error}

The current measurements show a high value in the neutral conductor. The measurement device determines its reference frequency on the frequency of the grid on the phase voltage of the first channel. This reference is used to determine the other values such as RMS values or Fourier analyses of voltage and current.

Since a stable base frequency is required in order to make correct measurement, possible malfunction of equipment can occur during measurement. The error is even more pronounced for the neutral conductor current.

$$
\begin{gathered}
U_{R M S}=\sqrt{\frac{1}{T} \sum_{0}^{T} u^{2}(t) \cdot \Delta t} \\
I_{R M S}=\sqrt{\frac{1}{T} \sum_{0}^{T} i^{2}(t) \cdot \Delta t}
\end{gathered}
$$

If the time step interval of the voltage (2) is higher than the time step interval of the current (3), and the RMS value of the current is calculated by the time step of the, calculations will result in higher RMS currents than the real RMS current.

For the calculation of both harmonic spectrum and RMS value of a signal a correct time step is needed. The THD(U) and RMS values of the voltage are correct since the time step of the voltage is used for calculating these values. Since the determination of both the THD(I) and RMS values of the current are based on the frequency of the voltage, these values will be calculated incorrect. As a consequence the current harmonics as shown in Figure 8 are not representing the real currents (Figure 10) and the RMS values of the currents will be not correct.

An electronic circuit breaker uses the same calculation principles in order to measure the current. As a consequence the device will calculate RMS currents higher than in reality, and the circuit breaker will trip. With half of the PV panels connected, the circuit breaker still will calculate wrong values of the current. However the error will not be high enough in order to trip on overload.

\section{SIMULATIONS}

To investigate and validate the measured effects in detail, a Matlab - Simulink ${ }^{\circledR}$ model of the installation is made, represented schematically in Figure 17. For that purpose, a single phase inverter is modeled. Three of these inverters are implemented in a three phase system. The power injection of the PV production is modeled by means of a constant DC current source, feeding each DC link capacitor. The inverters deliver power to the grid through a $\mathrm{Yy}_{0}$ transformer, according to the practical configuration.

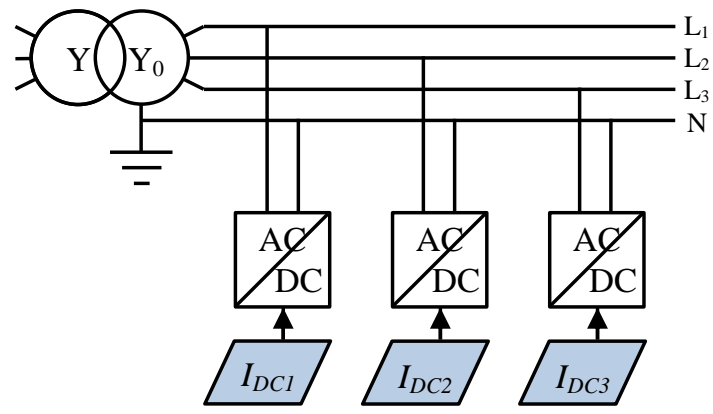

Figure 17: Schematic diagram of simulation model

The transformer only imposes line voltages. As a consequence the phase voltage will increase for the phase with a higher injection, with respect to the other phases. Simulations are performed for an injection of $4800 \mathrm{~W}, 4000 \mathrm{~W}$ and $4000 \mathrm{~W}$ in phase $\mathrm{L}_{1}, \mathrm{~L}_{2}$ and $\mathrm{L}_{3}$. Under ideal conditions without voltage disturbance, this should lead to a $\mathrm{AC}$ current of $20,9 \mathrm{~A}$ in phase $\mathrm{L}_{1}$ and $17,4 \mathrm{~A}$ in phase $\mathrm{L}_{2}$ and $\mathrm{L}_{3}$. In this case, the unbalanced current results in an increased phase voltage $\mathrm{U}_{\mathrm{L} 1}$. Since line voltages can't change, the two other phase voltages also will deviate with the same amount, as can be seen in the voltage vectors (Figure 18). The unbalance voltage in this case is $9 \mathrm{~V}$.

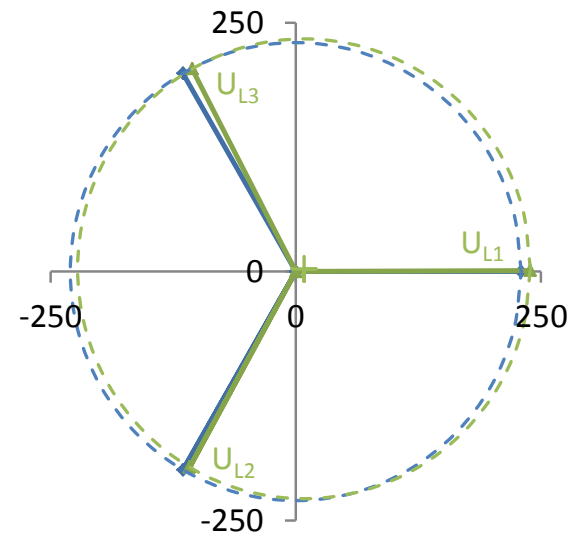

Figure 18: voltage unbalance due to asymmetric current injection at $120^{\circ}$

From this simplified simulation, it can be concluded that a unbalance in power injection will lead to an unbalance of the terminal voltage. This means that the $120^{\circ}$ phase shift will decrease to $119^{\circ}$ and $117^{\circ}$ for the two unaffected phases, as can be seen in Figure 18. Moreover, the PLL (Phase-Locked Loop) of each single phase inverter tries to inject the power with a power factor as close as possible to unity. So the rotation of the voltage vectors will effect in a rotation of the 
current vectors too. By doing this, the inverter is reinforcing the origin of the phase shift, until an equilibrium will be established. Due to this reason, the phase shift between $\mathrm{L}_{1}$ and $\mathrm{L}_{3}$ decreases further from $117^{\circ}$ to $115^{\circ}$ for this simulated case (Figure 19). Consequently, the unbalance voltage is increased from $9 \mathrm{~V}$ to $13 \mathrm{~V}$.
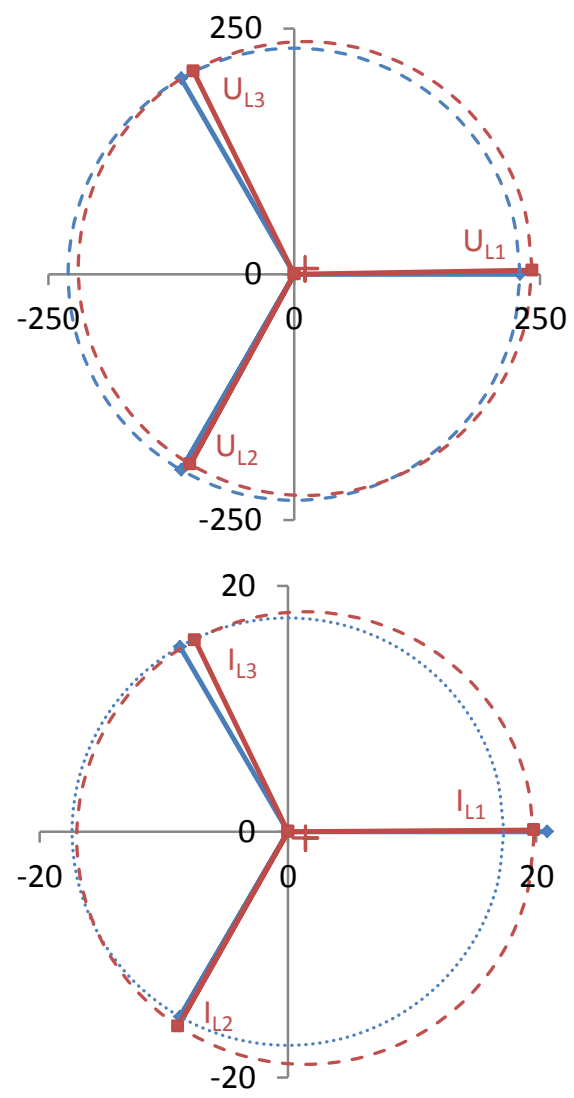

$\longrightarrow$ ideal situation $\longrightarrow$ simulation

Figure 19: voltage unbalance due to asymmetric current injection in phase with the voltage

\section{CONCLUSIONS AND FURTHER RESEARCH}

Sufficient unbalance in the current injection causes distortion of the phase voltage due to the zero sequence grid impedance. In case of high zero sequence impedance such as in $\mathrm{Yy}_{0}$ transformers high voltage unbalance will be found in case of small current unbalance. Also on variable load conditions flicker can occur.

In installations where only single phase inverters are used, a phase voltage distortion will cause additional current distortion. Current distortion will be not proportional to the voltage distortion. Consequently the zero crossings of voltage and current are not equal. So, the calculation of RMS and FFT currents will be incorrect. Since electronic circuit breakers use the same measurement and calculation algorithms as power analyzers a higher current is found with possible tripping of the circuit breaker.

In this practical case a solution is found by replacing the $\mathrm{Yy}_{0}$ transformer by a $\mathrm{Dy}_{0}$ transformer. As a result, the zero sequence field impedance is low and phase voltage remains constant. The circuit breaker will measure the correct current and does not trip. This has been practically implemented with success.

\section{REFERENCES}

[1] http://ec.europa.eu/clima/policies/brief/eu/package_en.htm

[2] B. Verhelst, J. Desmet, C. Debruyne, L. Vandevelde and H. Van Landeghem, "Technical and business economic study of photovoltaic systems”, ICREPQ 2010, 23-25 March, Granada

[3] Desmet J., Debruyne C., Vanalme J., Verhelst B., "Implementation of innovative sustainable energy sources and their implementation on the distribution network", ISBN 9789081549806, 2010.

[4] DIN VDE 0298 part 4, Recommended current-carrying capacity for sheathed and non sheathed cables for fixed wirings in and around buildings and for flexible cables and cords

[5] SMA Sunny boy 5000TL, http://www.sma.de/en/products/solarinverters/sunny-boy/sunny-boy-3000tl-4000tl-5000tl.html

[6] EN50160, "Voltage characteristics of electricity supplied by public distribution networks", 2007.

[7] Er Lee Wai Meng, Measurement of zero sequence impedance for threewinding transformers, The singapore engineer, 2010

[8] Phase to Phase, Three step transformers - applications, 01-125 pmo, 244-2001 